\title{
The Role of Astrocytes in Multiple Sclerosis
}

\author{
Gerald Ponath, Calvin Park and David Pitt* \\ Department of Neurology, Yale School of Medicine, New Haven, CT, United States
}

The role traditionally assigned to astrocytes in the pathogenesis of multiple sclerosis (MS) lesions has been the formation of the glial scar once inflammation has subsided. Astrocytes are now recognized to be early and highly active players during lesion formation and key for providing peripheral immune cells access to the central nervous system. Here, we review the role of astrocytes in the formation and evolution of MS lesions, including the recently described functional polarization of astrocytes, discuss prototypical pathways for astrocyte activation, and summarize mechanisms by which MS treatments affect astrocyte function.

Keywords: astrocytes, multiple sclerosis, neuroinflammation, NF-кB, risk variant, leukocyte recruitment

\section{OPEN ACCESS INTRODUCTION}

Edited by:

Edgar Meinl,

Ludwig-Maximilians-Universität

München, Germany

Reviewed by:

Chiara Cordiglieri,

Istituto Nazionale Genetica

Molecolare (INGM), Italy

Andreas Junker,

Universitätsklinikum Essen, Germany

${ }^{*}$ Correspondence:

David Pitt

david.pitt@yale.edu

Specialty section:

This article was submitted to

Multiple Sclerosis and

Neuroimmunology,

a section of the journal

Frontiers in Immunology

Received: 02 December 2017

Accepted: 25 January 2018

Published: 19 February 2018

Citation:

Ponath G, Park C and Pitt D

(2018) The Role of Astrocytes

in Multiple Sclerosis.

Front. Immunol. 9:217.

doi: 10.3389/fimmu.2018.00217
Multiple sclerosis (MS) is an autoimmune disease that targets the central nervous system (CNS) (1). It is the most common, non-traumatic neurological disorder in young patients and affects nearly 1 million people in the US alone (2). In the majority of MS patients, the disease manifests itself as episodes of neurological dysfunction that remit spontaneously [relapsing-remitting MS (RRMS)] (1). Pathologically, relapses are associated with focal, inflammatory demyelination in white and gray matter, characterized by infiltration with macrophages and T and B lymphocytes (3). Over two-thirds of patients eventually develop secondary progressive MS (SPMS), a disease stage that is believed to be driven by neurodegeneration, where patients experience slow and irreversible accumulation of disability, predominantly affecting ambulation and cognition $(1,4)$. In a small percentage of MS patients, progression sets in at disease onset, a disease course that is termed primary progressive MS (1). The pathophysiology of primary and secondary progression remains largely unexplained; however, multiple lines of evidence suggest that progressive MS is associated with chronic activation of the CNS innate immune system (5-7). The poor understanding of the pathomechanisms underlying progression is reflected in the current treatment options for MS, with 13 FDA-approved medications being available for RRMS, one moderately effective medication for primary progressive MS, and none for secondary progression (8).

Multiple sclerosis is the result of an interplay between environmental and genetic factors. Genome-wide association studies (GWASs) have identified over 230 variants associated with susceptibility for MS that all confer small increases in disease risk (9-11). Environmental factors associated with MS risk include smoking, childhood obesity, low vitamin D levels, infection with the Epstein-Barr virus, and possibly a high salt diet (12-14). The pathological hallmark of MS is the presence of focal inflammatory lesions characterized by primary demyelination and relative preservation of axons (15). Acute demyelinating lesions are populated by abundant foamy, myelin-laden macrophages and by lymphocytes that are located in the perivascular space and diffusely throughout the lesion area, albeit at much lower numbers than myeloid cells (15). Acutely demyelinating lesions eventually evolve into chronic active lesions, which are characterized by completed demyelination and astroglial scarring in the lesion center, and inflammatory cells at 
the lesion rim, possibly associated with low-grade demyelination (15). Finally, chronic silent lesions consist of astroglial scars with few or no inflammatory cells (15). Astrocytes have traditionally been assigned a bystander role, reacting only once demyelination is completed by forming a glial scar (16). However, recent literature suggests that astrocytes are early and highly active participants in MS lesion development (17-19). Astrocytes play multiple roles in the evolution of MS lesions, not only by recruiting lymphocytes $(19,20)$ and contributing to tissue damage (21-24) but also by confining inflammation and promoting lesion repair (18). In addition, astrocytes themselves sustain significant damage during the inflammatory process (16). This review focuses on the contributions of astrocytes to MS lesion formation. We discuss astrocytic phenotypes, prototypical pathways for astrocyte activation, including the impact of genetic risk variants for MS susceptibility on astrocyte responses, and mechanisms by which MS treatments affect astrocyte function.

\section{THE PHYSIOLOGICAL ROLE OF ASTROCYTES AND ASTROCYTE RESPONSES}

Astrocytes make up approximately $30 \%$ of glial cells in the CNS, where each astrocyte occupies a unique territory demarcated by non-overlapping, star-shaped processes that extend from the cell soma $(25,26)$. The distal end feet of these processes form the glia limitans when they envelop the parenchymal basal lamina associated with blood vessels or meninges $(18,25)$. The glia limitans contributes to the maintenance of blood-brain barrier $(\mathrm{BBB})$ integrity and forms a secondary barrier that further restricts entry of peripheral immune cells into the CNS $(16,27)$. Astrocytes are paramount for normal CNS functions, including maintenance of glutamate, extracellular potassium, and water homeostasis $(20,25)$. Astrocytes are functionally connected to adjacent astrocytes and to oligodendrocytes by gap junctions, thereby forming large syncytium-like glial networks that are composed of hundreds of cells (28). Together with neuronal synapses, astrocyte processes form so-called tripartite synapses, where one single astrocyte connects with tens of thousands of neuronal synapses (29) to regulate neuronal synaptic transmission, e.g., by releasing glutamate, D-serine, and ATP $(30,31)$. Astrocytes also prune synapses through phagocytosis (32) and modify gene expression, e.g., associated with neural plasticity, in surrounding neurons by secreting miRNA-containing exosomes (33). In addition, astrocytes secrete neurotrophic factors (34) and are metabolically coupled to neurons, releasing lactate for neuronal uptake and providing antioxidants such as glutathione and thioredoxin $(35,36)$. Astrocytes also participate in the production of neurosteroids, such as allopregnanolone, estrogen, and dehydroepiandrosterone (DHEA), that are synthesized in the nervous system, where they modulate neuronal excitability, promote myelination, and dampen pro-inflammatory responses in astrocytes (37-41). Moreover, in the healthy CNS, astrocytes contribute to an anti-inflammatory environment through constitutive low-level secretion of the anti-inflammatory cytokines TGF- $\beta$ (42) and IL-10 (43), expression of Fas ligand $(44,45)$, and induction of upregulation of the co-inhibitory cell surface receptor CTLA-4 on helper T cells (46).

Astrocyte reactivity in adaptive and innate immune responses can be triggered through oxidative or chemical stress, pro-inflammatory cytokines, damage-associated molecular patterns (DAMPs), released in the context of CNS tissue damage, and pathogen-associated molecular patterns (PAMPs), such as double-stranded RNA and bacterial membranous endotoxins, released from pathogens $(19,47,48)$. Stimulation of astrocytes induces or upregulates astrocytic secretion of cytokines, such as TNF- $\alpha$, IL-1 $\beta$, and IL-6; neurotrophic factors including nerve growth factor (NGF), brain-derived neurotrophic factor (BDNF), vascular endothelial growth factor (VEGF), and leukemia inhibitory factor (LIF) $(19,48-50)$; chemokines including CCL2, CCL20, and CXCL10; and $\beta$-defensins, antimicrobial peptides that can directly diminish the stability of bacterial membranes and stimulate various immune functions $(51,52)$. In addition, reactive astrocytes express cell adhesion molecules such as ICAM-1 and VCAM-1 (50), inducible nitric oxide synthase (iNOS) with concomitant production of reactive nitrogen species $(53,54)$, and the PAMP-recognizing toll-like receptor 3 (TLR3), while other TLRs remain low to undetectable (55-58). Activation of TLR3 triggers a predominantly neuroprotective response, characterized by secretion of growth and differentiation mediators as well as pro- and anti-inflammatory cytokines (58).

Astrocytes also constitutively express low amounts of MHC-II and the adhesion molecules LFA-1 (CD11a) and ICAM-1 (CD54) (59). Stimulation with IFN- $\gamma$ alone or in combination with TNF- $\alpha$ upregulates MHC-II, adhesion molecules, and co-stimulatory molecules B7-1 (CD80) and B7-2 (CD86) (60). Functional studies have shown that IFN- $\gamma$-treated murine astrocytes act as weak antigen-presenting cells, moderately activating $\mathrm{CD}^{+}$and $\mathrm{CD}^{+} \mathrm{T}$ cells. In contrast, cytokine-treated human astrocytes were not able to induce proliferation of encephalitogenic T cells, presumably because of lack of additional proliferation-inducing factors (59), suggesting interspecies differences in astrocytes. Furthermore, in the inflamed CNS, reactive astrocytes may contribute to B cell survival, maturation, and proliferation through production of B cell-activating factor of the TNF family (BAFF) (61-63). Other soluble factors secreted by astrocytes, such as IL-6 and IL-15, also support B cell survival (61). Finally, stimulation of astrocytes with cytokines diminishes their homeostatic and metabolic functions, resulting in impaired glutamate uptake, which may cause excitotoxicity, and in metabolic uncoupling from axons/neurons due to decreased release of lactate $(23,24$, 64-66) (Figure 1).

Reactive astrocytes have recently been categorized according to their transcriptome profiles as "A1" or "A2," in analogy to the "M1" and "M2" phenotype categories for macrophages (67). A1-type astrocytes, for which complement component 3 is an identifying marker, are induced by inflammation $(67,68)$, are abundant in MS and neurodegenerative diseases, including Alzheimer's and Parkinson's disease, and secrete a neurotoxin that has not yet been identified (67). In contrast, A2-type 


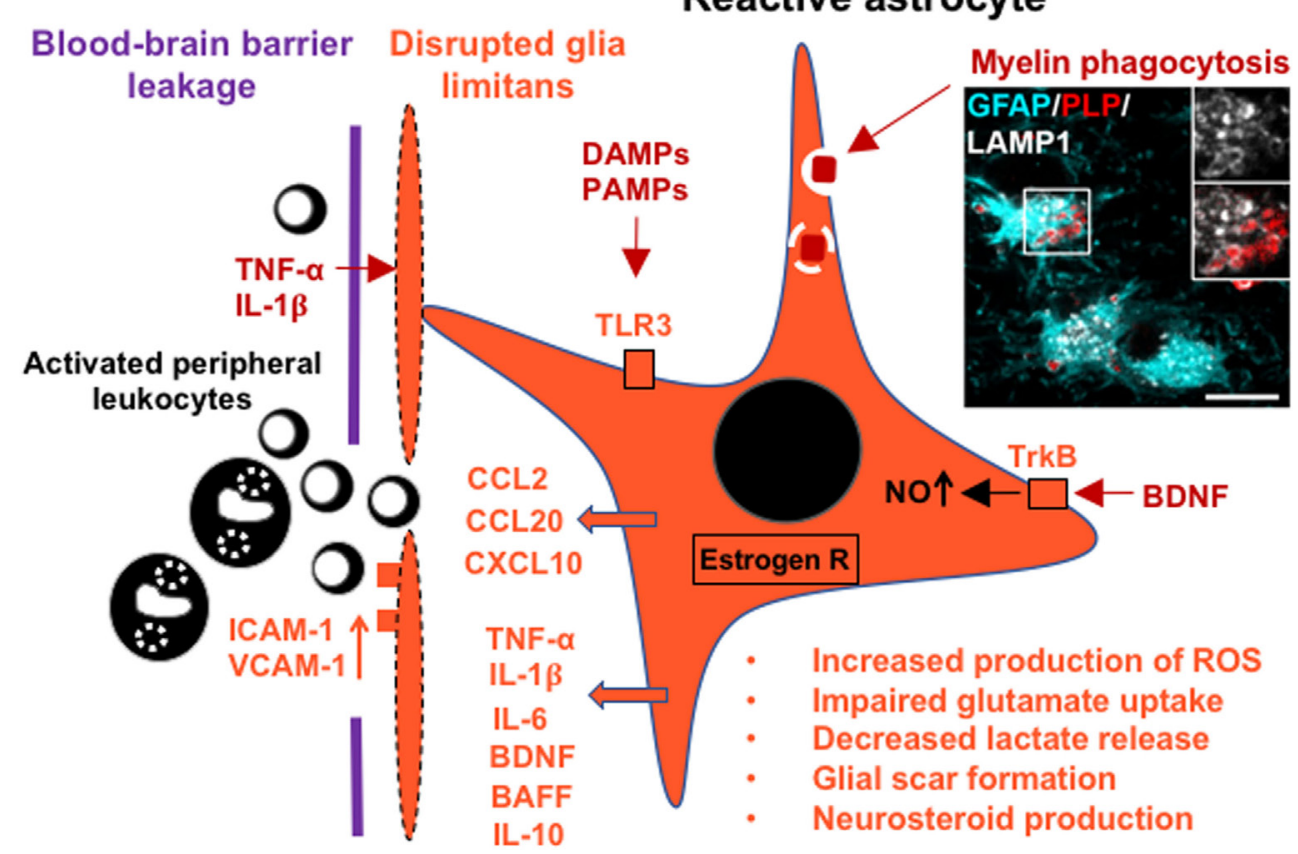

FIGURE 1 | Schematic of the glia limitans and a reactive astrocyte in multiple sclerosis (MS), indicating secretion of cytokines, recruitment of leukocytes across the blood-brain barrier, and upregulation of selected receptors that contribute to astrocyte responses and metabolic changes. Inset image shows a reactive hypertrophic astrocyte at the active rim of an MS lesion containing myelin debris within lysosomal ring structures [glial fibrillary acidic protein (GFAP), cyan; myelin proteolipid protein (PLP), red; lysosomal-associated membrane protein 1 (LAMP1), white]. Scale bar $=10 \mu \mathrm{m}$. The inset image was reproduced from Figure 1 of Ponath et al. (17) with the permission of Brain.

astrocytes are induced by ischemia and express neurotrophic factors (67). The concept of M1/M2 polarization is now considered an oversimplification and has been abandoned in favor of multiple, complex polarization states that do not necessarily align with a one-dimensional M1-M2 spectrum (69). Thus, while defining these phenotypes is an important step, reactive astrocytes may also exceed the A1-A2 dichotomy and assume a range of profiles with mixed $\mathrm{A} 1$ and $\mathrm{A} 2$ features (70). It has been proposed that although reactive astrocytes share common properties, they also display unique cellular and molecular features that are specific to different neuropathologies (70, 71). Moreover, distinct astrocytic phenotypes may coexist or develop sequentially during different phases of a pathological process: reactive astrocytes may first produce pro-inflammatory cytokines and reactive oxygen species in conjunction with hypertrophy and proliferation. In a second phase, astrocytes may promote anti-inflammatory and neuroregenerative functions through astrocyte-derived neurotrophic factors (72).

Thus, reactive astrocytes can mount powerful inflammatory responses that drive leukocyte recruitment to the CNS and thereby contribute to a successful defense against pathogens. Moreover, reactive astrocytes may change their response profiles over time, resulting in the secretion of anti-inflammatory cytokines and neurotrophins $(72,73)$. Astrocytosis can also aid in $\mathrm{BBB}$ repair and, depending on the severity of the injury, lead to the formation of glial scars that isolate the inflamed area, restrict damage and provide structural support (25).

\section{THE REACTIVE ASTROCYTE IN MS LESION PATHOLOGY}

Astrocytes are increasingly recognized as cells that critically contribute to the development of MS lesions. Previously, astrocytes were believed to react only at a late, post-inflammatory stage by forming a glial scar, but are now considered early and active players in lesion pathology $(16,17)$. In active lesions, astrocytes assume a hypertrophic morphology, characterized by massive enlargement of the cell soma and reduced process density (16). Typically, pronounced astroglial hypertrophy is indicative of substantial tissue injury and might be caused in MS lesions by oligodendrocyte loss and the resulting disruption of astrocyteoligodendrocyte networks $(16,28)$. In addition, hypertrophic astrocytes may themselves sustain substantial damage that leads to retraction or loss of glia limitans from the basal lamina around blood vessels, presumably further increasing access of immune cells to the CNS (16) (Figure 1).

Reactive astrocytes are present in the active margins of demyelinating lesions and extend into adjacent, normal-appearing white matter (NAWM), suggesting that they are early contributors to lesion development $(16,17)$. This view is supported by the observation in murine experimental autoimmune encephalomyelitis (EAE), an inflammatory demyelinating model of MS, that astrocytes in nascent lesions become activated before significant immune cell infiltration into the parenchyma takes place (74-76). Furthermore, we have shown that hypertrophic astrocytes at 
the leading edge of actively demyelinating MS lesions contain myelin debris (17). We have demonstrated that this myelin uptake induces astroglial NF- $\kappa \mathrm{B}$ signaling and secretion of cell-recruiting chemokines. Therefore, we hypothesized that uptake of damaged myelin by astrocytes may be an early trigger for their activation, leading to astrocyte-mediated influx of leukocytes at the very beginning of lesion development (17) (Figure 1). Given that astrocytes in MS lesions express MHC class II and co-stimulatory molecules CD80 and CD86 $(77,78)$, it is tempting to speculate that myelin phagocytosis by astrocytes results in the presentation of myelin antigens to T cells. However, since stimulated human astrocytes in culture fail to induce, and even inhibit, proliferation of T cells (79), we consider it unlikely that astrocytes act as competent antigen-presenting cells in MS lesions.

In MS, hypertrophic astrocytes express chemokines and cell adhesion molecules associated with macrophage/microglia and lymphocyte recruitment into the parenchyma (80-82). Their functional relevance to leukocyte recruitment has been well documented in EAE. For example, in mice with a conditional, astrocyte-specific gene deletion of CCL2, induction of EAE resulted in a less severe disease course with fewer macrophage and $\mathrm{T}$ cell infiltrates, and less activation of astrocytes and microglia (83). Similarly, mice with a genetic deletion of all ICAM-1 isoforms showed marked attenuation of EAE, with minimal cellular infiltration and demyelination in the spinal cord (84). Conversely, astrocyte-mediated recruitment of microglia to demyelinating lesions is also of benefit, as demonstrated in a demyelination model using the oligodendrocyte toxin cuprizone, which does not disrupt the BBB or involve peripheral immune cell infiltration (85). Genetic ablation of astrocytes in mice treated with cuprizone prevented the recruitment of microglia cells to the site of demyelination, leading to delayed removal of myelin debris, impaired remyelination, and reduced proliferation of oligodendrocyte precursor cells (86). Thus, activated astrocytes are key regulators for the removal of damaged myelin, which is needed before remyelination can take place (86).

In addition, BAFF production by reactive astrocytes may contribute to the pathogenesis of MS by promoting B cell survival and proliferation in the CNS $(61,62)$. BAFF levels were shown to be increased in the CSF of MS patients compared to healthy controls (87). Moreover, BAFF mRNA was strongly upregulated in MS lesions, comparable to levels observed in lymphatic tissues, and BAFF was found to be expressed in reactive astrocytes, adjacent to inflammatory cells that expressed BAFF receptors (63). Given the continuous presence of antigen-experienced B cell clones in the CNS of MS patients (88) and the development of meningeal B cell follicles in progressive MS (89), astroglial production of BAFF may be a major factor to sustain these cells and to drive B cell-related pathology.

Reactive astrocytes likely contribute to tissue damage in MS through impaired glutamate handling and redox homeostasis. Glutamate concentrations were shown to be elevated in acute lesions of MS patients using in vivo MR spectroscopy (90). Moreover, a GWAS has linked specific risk variants associated with glutamate metabolism to increased cortical glutamate concentrations and poor disease outcomes in MS patients (91).
In $\mathrm{EAE}$, disease severity as well as oligodendrocyte and neuronal death were ameliorated through treatment with antagonists to the AMPA/Kainate or NMDA type of glutamate receptors $(23,24)$.

A recent study in a chronic progressive model of EAE has shown that astrocytes produce and are stimulated by the sphingolipid lactosylceramide (LacCer) (7). LacCer induces production of pro-inflammatory cytokines and iNOS in astrocytes and promotes pathology during experimental spinal cord injury (92). In EAE, LacCer was found to control the recruitment and activation of microglia and CNS-infiltrating monocytes by astrocytes. In addition, inhibition of LacCer synthesis suppressed CNS innate immunity and neurodegeneration. Finally, LacCer and the LacCer synthase $\beta$-1,4-galactosyltransferase 6 (B4GALT6) were detected in reactive astrocytes within MS lesions (7), suggesting that the B4GALT6-LacCer pathway is relevant to human disease.

Although reactive astrocytes drive inflammatory and neurotoxic responses in MS lesions, they may also dampen inflammation and promote neuroprotection and lesion repair. A factor produced by astrocytes and neurons in the normal CNS, which has CNS-trophic effects, is $\operatorname{BDNF}(93,94)$. In EAE, astrocyte-specific deletion of BDNF resulted in a more severe clinical course with increased axonal loss (95). Moreover, in the cuprizone mouse model, enhanced BDNF production by astrocytes, induced by stimulation of metabotropic glutamate receptors, resulted in enhanced remyelination (96). However, a separate study demonstrated that signaling through the BDNF receptor TrkB in astrocytes leads to production of nitric oxide (NO) (97). EAE induced in mice with astrocyte-specific genetic deletion of TrkB had ameliorated disease severity, concomitant with reduced expression of astrocytic and lesional iNOS (97). These data indicate that BDNF released by astrocytes not only elicits neuroprotective effects in other cell types but also stimulates production and release of toxic NO in astrocytes themselves. In MS lesions, BDNF is primarily present in immune cells and reactive astrocytes (98), while the BDNF receptor $\operatorname{TrkB}$ was strongly upregulated in reactive astrocytes and in neurons in the immediate lesion vicinity (98). This suggests a possible dual protective and degenerative role for BDNF.

Astrocytes are susceptible to neurosteroids, such as estrogen and DHEA, which downregulate pro-inflammatory responses in reactive astrocytes (99-101). This mechanism plays a significant role in EAE where treatment of mice with an estrogen receptor- $\alpha$ $(\mathrm{ER} \alpha)$ ligand substantially ameliorated clinical symptoms, inflammatory infiltrates, and axonal loss $(102,103)$. These beneficial effects were mediated entirely through ER $\alpha$ expressed by astrocytes, as they were abolished in EAE induced in mice with conditional, astrocyte-specific deletion of $\operatorname{ER} \alpha$ (103). In MS lesions, $\mathrm{ER} \alpha$, aromatase, an enzyme involved in estrogen synthesis, and progesterone receptor were found to be upregulated in reactive astrocytes (104), suggesting that neurosteroid synthesis by reactive astrocytes as well as astrocytic responses to neurosteroids are part of an endogenous protective mechanism. On the other hand, a recent study found that the neurosteroids allopregnanolone and DHEA were substantially downregulated in EAE and in NAWM of autopsied MS tissue (105). Provided that astrocytes are the main steroidogenic cells in the brain (38), these 
data may point toward impaired synthesis of both neurosteroids by astrocytes in MS.

In addition, TLR signaling may play a neuroprotective role in EAE and by extension, in MS, although this effect might not be astrocyte-specific. Systemic administration of the TLR3 agonist polyinosinic:polycytidylic acid (poly I:C) in EAE suppresses relapsing demyelination through induction of IFN- $\beta$ and other immune regulatory effects (106). Furthermore, TLR4 knockout mice exhibited more severe EAE symptoms than wild-type mice, associated with increased priming of encephalitogenic Th17 cells (107). In MS lesions, TLR3 and 4 are expressed by microglia and astrocytes, where astroglial TLR expression is particularly prominent at later stages of inflammation, which may be instrumental in mitigating inflammation and promote tissue repair $(56,58)$.

Furthermore, following acute inflammation and demyelination, hypertrophic astrocytes eventually form a glial scar in the center of white matter lesions (25). While scars have been considered as barriers to tissue regeneration (16), they also provide beneficial features and contribute to recovery from CNS insults (25). For example, glial scars support demyelinated axons, help restore $\mathrm{BBB}$ function, and confine inflamed areas, preventing the spread of immune cells and toxic levels of extracellular ions, metabolites, or DAMPs into healthy tissues or areas of repair $(16,25)$.

Recent studies have implicated gut microbiota in immunological disorders including MS and its animal model, EAE $(108,109)$. The microbiome has emerged as a regulator of $\mathrm{BBB}$ integrity, where the absence of normal gut flora leads to disorganization of tight junctions in endothelial cells (110), and the production of short-chain fatty acids by bacteria corrects BBB dysfunction $(111,112)$. However, to date, astrocytes have not been found to mediate these effects.

\section{SIGNALING PATHWAYS IN ASTROCYTES}

Astrocyte reactivity is regulated by key canonical signaling cascades, among which the NF- $\kappa \mathrm{B}$ pathway is pivotal for establishing neuroinflammation (113) (Figure 2). NF- $\kappa B$ is a master regulator of innate and adaptive immunity that controls cell survival, differentiation, and proliferation (114). Astrocytic NF- $\kappa B$ signaling is directly activated through stimulation with the pro-inflammatory cytokines TNF- $\alpha$ and IL-1 $\beta$ (113), through TLR signaling and various other agents including phagocytosed myelin, mitogens, and free radicals $(17,113,115,116)$. NF- $\mathrm{KB}$ signaling in astrocytes plays a critical role for initiating and maintaining inflammation in the CNS. Transgenic mice with astrocyte-specific inactivation of NF- $\kappa \mathrm{B}$ display dramatic amelioration of tissue damage and clinical impairment following induction of EAE, spinal cord injury, or ischemic retinal injury compared to wild-type mice (117-119). Similarly, ablation of IL-17-induced Act1 signaling in astrocytes, which abolishes IL-17-mediated NF- $\mathrm{KB}$ activation, reduces the recruitment of lymphocytes and macrophages and markedly ameliorates disease severity in EAE (120).

Interestingly, microbial flora and its products have been shown to control NF- $\mathrm{BB}$ signaling through conversion of dietary tryptophan into agonists of aryl hydrocarbon receptor (AHR), which is highly expressed by astrocytes (121). AHR suppresses the classical activation pathways of NF- $\mathrm{BB}$ through competitive binding to the NF- $\kappa B$ subunit p65 (122). Induction of EAE in mice with astrocyte-specific genetic knockout of AHR [glial fibrillary acidic protein (GFAP)-AHR ${ }^{-}$] resulted in increased expression of chemokines, cytokines and pro-inflammatory markers and an exacerbated disease course compared to wild type animals. Moreover, mice fed with a tryptophan-depleted diet exhibited a more severe EAE course, which could not be reversed by addition of tryptophan in GFAP-AHR- mice. In MS, AHR expression was upregulated in active and chronic MS lesions and localized to $\mathrm{GFAP}^{+}$astrocytes; however, this might not translate into AHR-dependent downregulation of astrocyte activation, because expression of the AHR transcriptional target CYP1B1 was decreased in MS lesions and NAWM, suggesting that this pathway is defective in MS (121).

We have recently shown that an MS risk variant, rs7665090, which increases NF- $\mathrm{KB}$ signaling in lymphocytes (123), substantially affects astrocyte reactivity in cell culture and MS white matter lesions (81). Astrocytes derived from induced pluripotent stem cells, obtained from MS patients carrying the risk variant, showed increased NF- $\kappa$ B activation, chemokine and cell adhesion molecule expression, as well as impaired glutamate uptake and reduced lactate release. In addition, the risk variant was associated with significantly higher numbers of infiltrating lymphocytes in white matter MS lesions and with an increased lesion load on MRI in MS patients (81). Therefore, this NF- $\kappa B-$ relevant risk variant promotes pro-inflammatory changes in astrocytes that might help target aberrant immune responses to the CNS. This challenges the view that MS is mediated solely through dysregulation of lymphocytes and highlights the importance of astroglial NF- $\kappa B$ signaling for lesion formation (81) (Figure 2).

An important but less elucidated signaling cascade for regulation of astrocyte activation in MS is the STAT3 pathway (Figure 2). STAT3 activity is generally upregulated in response to CNS inflammation and damage (124). In astrocytes, STAT3 signaling is induced by both pro- and anti-inflammatory molecules, including IFN- $\gamma$ and cytokines of the IL- 6 family, that bind to the gp130 cell-surface receptor to induce STAT3 phosphorylation (124-127). STAT3 signaling in astrocytes plays a beneficial role in CNS inflammation, as demonstrated in mice with conditional, astrocyte-specific knockout of STAT3, where spinal cord injury lesions exhibited increased demyelination, contained more infiltrating dendritic cells, and had attenuated astrocyte hypertrophy and glial scar formation $(128,129)$. Similarly, in EAE, disease severity was exacerbated in mice with astrocyte-specific knockout of the STAT3-activating gp130 signal transducer, with larger areas of demyelination and increased infiltration of reactive T-lymphocytes (130). Moreover, activated astrocytes have been shown to provide neuronal protection $v i a$ ERK(131) and/orSTAT3 signaling during inflammation (132). This was demonstrated in an in vivo model of acute LPS/IFN- $\gamma$-induced neuroinflammation, where STAT3 and ERK signaling induced IL- 6 production, which protected against neuronal apoptosis (133). Despite its importance as a neurotrophin in the CNS, IL-6 is also known to promote MS lesion development when produced in excess (134, 135). Specifically, IL-6 inhibits differentiation of naïve $T$ cells into regulatory $\mathrm{T}$ cells and promotes their differentiation into 


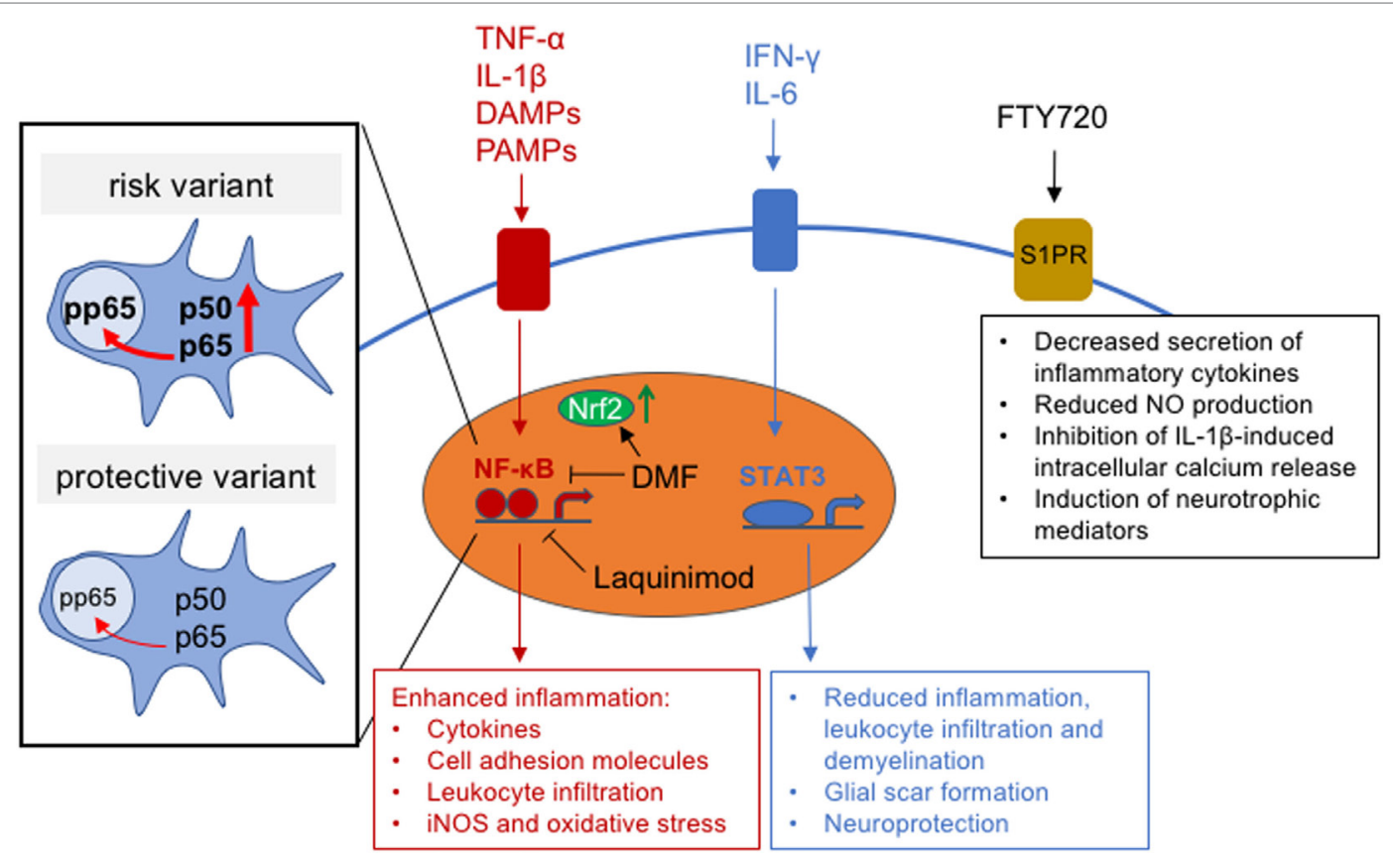

FIGURE 2 | Intracellular astrocytic signaling pathways and effects of multiple sclerosis (MS) treatments on signaling function. Inset shows schematic of the effect of

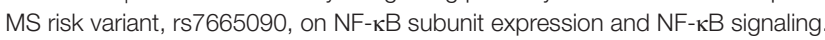

Th17 helper cells, which are considered to be major mediators of MS pathology (134). Thus, IL-6 levels above or below a certain threshold may determine its role as either a growth factor and activator of STAT3-mediated anti-inflammatory function, or as a suppressor of regulatory $\mathrm{T}$ cell differentiation and enhancer of pro-inflammatory helper $\mathrm{T}$ cell activity. Therefore, understanding the dynamics of IL-6 production in CNS lesions may help to predict the effectiveness of STAT3 signaling as a suppressor of lesion pathology.

\section{DIRECT MODULATION OF REACTIVE ASTROCYTE ACTIVITY BY MS TREATMENTS}

As discussed above, activated astrocytes play multiple pivotal roles during inflammation, including regulation of leukocyte trafficking, release of neurotoxic factors, confinement of inflammation, and promotion of neuroprotection and tissue repair. This makes astrocytes obvious therapeutic targets in MS. Ideally, such treatments would take into account the multi-functionality of astrocytes to block detrimental responses and/or enhance regenerative properties. Current MS therapies that are known to cross the BBB and modulate astrocyte function are laquinimod, which is currently being developed as an MS treatment, dimethyl fumarate (DMF; Tecfidera ${ }^{\circledR}$ ) and fingolimod (FTY720; Gilenya ${ }^{\circledR}$ )/ siponimod. In clinical studies, siponimod and laquinimod have shown a positive impact on progressive MS and brain atrophy, respectively. Since progressive MS is believed to be driven in part by chronic glial activation, these studies provide circumstantial evidence that astrocyte activation may contribute to progressive pathology. Below, we provide details of how each of these compounds impacts astrocytes.

\section{Laquinimod}

Laquinimod is a small quinolone derivative of the immunomodulatory compound linomide. Laquinimod was initially tested in RRMS, where it led to moderate effects on the reduction of relapse rates as a primary study endpoint. However, significant effects were observed on brain atrophy and disease progression (136). This led to a clinical trial of laquinimod in primary progressive MS (ARPEGGIO trial), which is still ongoing (137).

While the precise molecular targets of laquinimod are not well defined, recent data suggests that laquinimod activates genes associated with the transcription factor aryl hydrocarbon receptor (AHR, see above) (138). AHR target genes encode for drug-metabolizing enzymes and proteins controlling cell proliferation, differentiation, and apoptosis $(139,140)$. Additionally, cross talk between AHR and other signaling pathways, including epidermal growth factor receptor (EGFR) (141, 142), protein kinase A (PKA) $(143,144)$, and NF- $\mathrm{KB}$ signaling $(144,145)$, has been reported (146). Accordingly, AHR modulates the differentiation and function of many cell populations, several of which play an important role in neuroinflammation. In mouse EAE, laquinimod exerts effects on the peripheral immune system, where it downregulates pro-inflammatory T cell responses (147, 148), and on CNS cells. Genetic deletion of AHR in the immune system fully abrogated the treatment effect of laquinimod on 
EAE, while deletion of AHR in the CNS partially abrogated this effect (138). In a separate study, laquinimod markedly reduced $\mathrm{NF}-\mathrm{\kappa B}$ signaling and pro-inflammatory activation of astrocytes, but not of microglia in vitro (Figure 2). In the cuprizone model of demyelination, laquinimod prevented demyelination, microglial activation, $\mathrm{T}$ cell infiltration, and axonal transection; this effect was attributed to in vivo attenuation of NF- $\kappa$ B signaling in astrocytes (149). Laquinimod exhibits additional modes of action including neuroprotection, as demonstrated in EAE, where conditional deletion of BDNF in myeloid and T cells partially abrogated the beneficial effect of laquinimod. Similarly, laquinimod treatment of MS patients was found to increase expression of BDNF in serum (150). Taken together, current data suggests that laquinimod exerts effects on multiple cell types during CNS inflammation. A key mechanism mediated by laquinimod is the downregulation of pro-inflammatory responses in astrocytes. Thus, the beneficial effects of laquinimod on brain atrophy and disability progression in MS patients may at least partially be explained by its direct effect on astrocytes.

\section{Dimethyl Fumarate}

Dimethyl fumarate is the methyl ester of fumaric acid and was FDA-approved for the treatment of relapsing forms of MS in 2013. In placebo-controlled clinical trials, Tecfidera ${ }^{\circledR}$ reduced the relapse rate in MS patients by approximately $50 \%$ and disability progression by $38 \%$ in one trial but not in a separate, parallel trial $(151,152)$. The effect of Tecfidera ${ }^{\circledR}$ on SPMS is unclear, as a phase III clinical trial was initiated but terminated early due to restructuring of the drug's manufacturer, Biogen (153). DMF activates the Nrf2 transcription factor, which targets antioxidant response element (ARE) genes coding for antioxidant enzymes that reduce oxidative stress (154). DMF induces Nrf2 through glutathione depletion and direct binding to the Nrf2 repressor Kelch-like ECH-associated protein 1 (KEAP1) (155-158). Moreover, DMF acts as a potent inhibitor of NF- $\mathrm{KB}$ signaling (159) and has been shown to modify DMF-sensitive cysteine residues in human T cells, which inhibits T cell activation (160)

(Figure 2).

In the peripheral immune system, DMF reduces lymphocyte counts, in particular cytotoxic and effector T cells, and inhibits activation of antigen-presenting cells (161). In the CNS, a major effect of DMF is the upregulation of Nrf2 in astrocytes, which is protective against oxidative injury via upregulation of oxidative stress-induced growth inhibitor 1 (162). This effect might ameliorate astrocytic damage in active lesions, including the retraction of perivascular astrocyte end feet along basal lamina (16), to reduce leakage across the $\mathrm{BBB}$ and the cortical surface (163). DMF also inhibits secretion of pro-inflammatory cytokines and chemokines by astrocytes and microglial cells, independent of changes in antioxidant gene expression (164). Therefore, in addition to its effect on the peripheral immune system, DMF has a direct impact on the CNS that involves protective and antiinflammatory effects on astrocytes.

\section{Fingolimod and Siponimod}

FTY720/fingolimod(2-amino-2[2-(4-octylphenyl)ethyl]propane1,3-diol hydrochloride; Gilenya $\left.{ }^{\circledR}\right)$ is a non-specific sphingosine-I phosphate (S1P) modulator. In clinical trials with RRMS patients, FTY720 reduced the annualized relapse rate by $48-55 \%$ and decreased risk of disability progression by $28 \%$ in one study, while having no significant effect on disability in another (165, 166). With regards to primary progressive MS, a recent trial demonstrated that FTY720 had no beneficial effects on disability progression or whole-brain atrophy (167). However, Siponimod, a selective modulator of the $\mathrm{S}_{1} \mathrm{P}_{1}$ and $\mathrm{S}_{1} \mathrm{P}_{5}$ receptors, did slow disability progression in SPMS in a phase III clinical trial (168).

The main effect of FTY720 on the peripheral immune system is the internalization and degradation of the $\mathrm{S} 1 \mathrm{P}$ receptor on lymphocytes, which results in impaired responses to the S1P gradient in lymph nodes and prevents lymphocyte egress $(169,170)$. In the CNS, S1P receptors play a number of roles in brain cell function, including astrocyte proliferation and migration $(171,172)$, oligodendrocyte differentiation and survival $(173,174)$, and neurite outgrowth and neurogenesis (175-177). The mechanism most relevant to MS and its animal model, EAE, involves $\mathrm{S}_{1} \mathrm{P}_{1}$ receptor signaling in astrocytes, which has been demonstrated in conditional null mouse mutants lacking $\mathrm{S}_{1} \mathrm{P}_{1}$ in astrocytes. When induced to develop EAE, these mice showed a substantial reduction in disease severity, which was not further affected through additional FTY720 treatment, suggesting that the main effect of FTY720 in EAE involves modulation of astrocyte function but not the arrest of lymphocytes in lymph nodes (178). In contrast, conditional deletion of $\mathrm{S}_{1} \mathrm{P}_{1}$ in neuronal cell lineages had no impact on EAE severity or the efficacy of FTY720 to suppress EAE. Astrocytes mainly express $\mathrm{S}_{1} \mathrm{P}_{1}$ and $\mathrm{S}_{1} \mathrm{P}_{3}$ as well as other subtypes at low levels $(171,179)$. Expression of both receptors is markedly increased in reactive astrocytes in active and chronic MS lesions. Moreover, treatment of cultured human astrocytes with FTY720 limits secretion of inflammatory cytokines (180), reduces NO production (181), induces neurotrophic mediators, and inhibits TNF- $\alpha$-induced inflammatory gene expression (182). Modulation of astrocytic intracellular pathway function induced by FTY720 includes enhanced expression of calcium-regulating proteins and inhibition of calcium release induced by the pro-inflammatory mediator IL-1 $\beta$ (183) (Figure 2). This data implicates $\mathrm{S}_{1} \mathrm{P}_{1}$ signaling in astrocytes as a major contributor to the pathogenesis of EAE and as the main therapeutic target of FTY720 (184). Thus, the efficacy of Siponimod, a modulator of the $\mathrm{S}_{1} \mathrm{P}_{1}$ and $\mathrm{S}_{1} \mathrm{P}_{5}$ receptors, in slowing disability accumulation in SPMS may be mediated through its direct effect on astrocytes.

Other MS therapies, such as teriflunomide (Aubagio $\left.{ }^{\circledR}\right)(185$, 186) and IFN- $\beta$ (Avonex ${ }^{\circledR}$, Betaseron $^{\circledR}$, Rebif $\left.^{\circledR}\right)$, have been shown to inhibit astroglial immune responses, the latter by inducing astroglial expression of AHR (121). However, teriflunomide and IFN- $\beta$ have limited or no BBB penetrance $(187,188)$, making it unlikely that these drugs exert continuous, direct effects on CNSresident cells.

\section{CONCLUSION}

Astrocytes play an instrumental role in the formation of MS lesions through a multitude of functional changes associated 
with their activation. Astrocytes are early responders in nascent white matter lesions, are the main recruiters of lymphocytes, and act themselves as immunocompetent cells that contribute to innate immunity. Moreover, astrocytes not only can adopt a neurotoxic phenotype, but also confine inflammation through scar formation and can promote neuroprotection and tissue repair. Astrocytic dysfunction associated with a genetic MS risk variant further suggests that astrocyte-mediated processes are causative in lesion pathology. Thus, while MS is driven by dysfunction of the peripheral immune system, CNS cells such as astrocytes may contribute to MS pathology by targeting dysregulated immune responses to the CNS. Finally, MS medications that impact astrocytes have shown efficacy in both relapsing-remitting and

\section{REFERENCES}

1. Nylander A, Hafler DA. Multiple sclerosis. J Clin Invest (2012) 122:1180-8. doi:10.1172/JCI58649

2. Wallin MT. The prevalence of multiple sclerosis in the united states: a population-based healthcare database approach. ECTRIMS Online Libr (2017) 26:199999.

3. Frohman EM, Racke MK, Raine CS. Multiple sclerosis - the plaque and its pathogenesis. N Engl J Med (2006) 354:942-55. doi:10.1056/NEJMra052130

4. Hafler DA. Multiple sclerosis. J Clin Invest (2004) 113:788-94. doi:10.1172/ JCI 21357

5. Lassmann H, van Horssen J, Mahad D. Progressive multiple sclerosis: pathology and pathogenesis. Nat Rev Neurol (2012) 8:647-56. doi:10.1038/ nrneurol.2012.168

6. Kutzelnigg A, Lucchinetti CF, Stadelmann C, Bruck W, Rauschka H, Bergmann $\mathrm{M}$, et al. Cortical demyelination and diffuse white matter injury in multiple sclerosis. Brain (2005) 128:2705-12. doi:10.1093/brain/awh641

7. Mayo L, Trauger SA, Blain M, Nadeau M, Patel B, Alvarez JI, et al. Regulation of astrocyte activation by glycolipids drives chronic CNS inflammation. Nat Med (2014) 20:1147-56. doi:10.1038/nm.3681

8. Soelberg Sorensen P. Safety concerns and risk management of multiple sclerosis therapies. Acta Neurol Scand (2017) 136:168-86. doi:10.1111/ ane. 12712

9. Sawcer S, Hellenthal G, Pirinen M, Spencer CC, Patsopoulos NA, Moutsianas L, et al. Genetic risk and a primary role for cell-mediated immune mechanisms in multiple sclerosis. Nature (2011) 476:214-9. doi:10.1038/ nature 10251

10. Beecham AH, Patsopoulos NA, Xifara DK, Davis MF, Kemppinen A, Cotsapas C, et al. Analysis of immune-related loci identifies 48 new susceptibility variants for multiple sclerosis. Nat Genet (2013) 45:1353-60. doi:10.1038/ng.2770

11. Farh KK-H, Marson A, Zhu J, Kleinewietfeld M, Housley WJ, Beik S, et al. Genetic and epigenetic fine mapping of causal autoimmune disease variants. Nature (2015) 518:337-43. doi:10.1038/nature13835

12. Ascherio A. Environmental factors in multiple sclerosis. Expert Rev Neurother (2013) 13:3-9. doi:10.1586/14737175.2013.865866

13. Hernandez AL, Kitz A, Wu C, Lowther DE, Rodriguez DM, Vudattu N, et al. Sodium chloride inhibits the suppressive function of FOXP3+ regulatory T cells. J Clin Invest (2015) 125:4212-22. doi:10.1172/JCI81151

14. O'Gorman C, Lucas R, Taylor B. Environmental risk factors for multiple sclerosis: a review with a focus on molecular mechanisms. Int J Mol Sci (2012) 13:11718-52. doi:10.3390/ijms130911718

15. Kuhlmann T, Ludwin S, Prat A, Antel J, Bruck W, Lassmann H. An updated histological classification system for multiple sclerosis lesions. Acta Neuropathol (2017) 133:13-24. doi:10.1007/s00401-016-1653-y

16. Brosnan CF, Raine CS. The astrocyte in multiple sclerosis revisited. Glia (2013) 61:453-65. doi:10.1002/glia.22443

17. Ponath G, Ramanan S, Mubarak M, Housley W, Lee S, Sahinkaya FR, et al. Myelin phagocytosis by astrocytes after myelin damage promotes lesion pathology. Brain (2017) 140:399-413. doi:10.1093/brain/aww298 phase III clinical trials of progressive MS, providing further circumstantial evidence that activation of astrocytes contributes to both pathologies.

\section{AUTHOR CONTRIBUTIONS}

GP, CP and DP wrote the manuscript.

\section{FUNDING}

DP is supported by the National Multiple Sclerosis Society (RG1610-26049) and the National Institutes of Health Grants R01 NS102267, R01 NS090464 and R01 NS095562.

18. Sofroniew MV. Astrocyte barriers to neurotoxic inflammation. Nat Rev Neurosci (2015) 16:249-63. doi:10.1038/nrn3898

19. Farina C, Aloisi F, Meinl E. Astrocytes are active players in cerebral innate immunity. Trends Immunol (2007) 28:138-45. doi:10.1016/j.it.2007.01.005

20. Ransohoff RM, Brown MA. Innate immunity in the central nervous system. J Clin Invest (2012) 122:1164-71. doi:10.1172/JCI58644

21. Karadottir R, Cavelier P, Bergersen LH, Attwell D. NMDA receptors are expressed in oligodendrocytes and activated in ischaemia. Nature (2005) 438:1162-6. doi:10.1038/nature04302

22. Micu I, Jiang Q, Coderre E, Ridsdale A, Zhang L, Woulfe J, et al. NMDA receptors mediate calcium accumulation in myelin during chemical ischaemia. Nature (2006) 439:988-92. doi:10.1038/nature04474

23. Pitt D, Werner P, Raine CS. Glutamate excitotoxicity in a model of multiple sclerosis. Nat Med (2000) 6:67-70. doi:10.1038/71555

24. Smith T, Groom A, Zhu B, Turski L. Autoimmune encephalomyelitis ameliorated by AMPA antagonists. Nat Med (2000) 6:62-6. doi:10.1038/71548

25. Sofroniew MV, Vinters HV. Astrocytes: biology and pathology. Acta Neuropathol (2010) 119:7-35. doi:10.1007/s00401-009-0619-8

26. von Bartheld CS, Bahney J, Herculano-Houzel S. The search for true numbers of neurons and glial cells in the human brain: a review of 150 years of cell counting. J Comp Neurol (2016) 524:3865-95. doi:10.1002/cne.24040

27. Horng S, Therattil A, Moyon S, Gordon A, Kim K, Argaw AT, et al. Astrocytic tight junctions control inflammatory CNS lesion pathogenesis. J Clin Invest (2017) 127:3136-51. doi:10.1172/JCI91301

28. Orthmann-Murphy JL, Abrams CK, Scherer SS. Gap junctions couple astrocytes and oligodendrocytes. J Mol Neurosci (2008) 35:101-16. doi:10.1007/ s12031-007-9027-5

29. Ventura R, Harris KM. Three-dimensional relationships between hippocampal synapses and astrocytes. J Neurosci (1999) 19:6897.

30. Bezzi P, Volterra A. A neuron-glia signalling network in the active brain. Curr Opin Neurobiol (2001) 11:387-94. doi:10.1016/S0959-4388(00)00223-3

31. Santello M, Volterra A. Neuroscience: astrocytes as aide-memoires. Nature (2010) 463:169-70. doi:10.1038/463169a

32. Chung W-S, Allen NJ, Eroglu C. astrocytes control synapse formation, function, and elimination. Cold Spring Harb Perspect Biol (2015) 7:a020370. doi: $10.1101 /$ cshperspect.a020370

33. Lafourcade C, Ramírez JP, Luarte A, Fernández A, Wyneken U. MiRNAs in astrocyte-derived exosomes as possible mediators of neuronal plasticity. J Exp Neurosci (2016) 10:1-9. doi:10.4137/JEN.S39916

34. Magistretti PJ. Neuron-glia metabolic coupling and plasticity. J Exp Biol (2006) 209:2304-11. doi:10.1242/jeb.02208

35. Masutani H, Bai J, Kim YC, Yodoi J. Thioredoxin as a neurotrophic cofactor and an important regulator of neuroprotection. Mol Neurobiol (2004) 29:229-42. doi:10.1385/MN:29:3:229

36. Anderson CM, BergherJP, Swanson RA. ATP-induced ATP release from astrocytes. J Neurochem (2004) 88:246-56. doi:10.1111/j.1471-4159.2004.02204.x

37. Akwa Y, Sananès N, Gouézou M, Robel P, Baulieu EE, Le Goascogne C. Astrocytes and neurosteroids: metabolism of pregnenolone and dehydroepiandrosterone. Regulation by cell density. J Cell Biol (1993) 121:135-43 doi:10.1083/jcb.121.1.135 
38. Zwain IH, Yen SS. Neurosteroidogenesis in astrocytes, oligodendrocytes, and neurons of cerebral cortex of rat brain. Endocrinology (1999) 140:3843-52. doi:10.1210/endo.140.8.6907

39. Reddy DS. Neurosteroids: endogenous role in the human brain and therapeutic potentials. Prog Brain Res (2010) 186:113-37. doi:10.1016/B978-0444-53630-3.00008-7

40. Schumacher M, Hussain R, Gago N, Oudinet J-P, Mattern C, Ghoumari AM. Progesterone synthesis in the nervous system: implications for myelination and myelin repair. Front Neurosci (2012) 6:10. doi:10.3389/ fnins.2012.00010

41. Kipper-Galperin M, Galilly R, Danenberg HD, Brenner T. Dehydroepiandrosterone selectively inhibits production of tumor necrosis factor $\alpha$ and Interlukin-6 in astrocytes. Int J Dev Neurosci (1999) 17:765-75. doi:10.1016/ S0736-5748(99)00067-2

42. John GR, Lee SC, Brosnan CF. Cytokines: powerful regulators of glial cell activation. Neuroscientist (2003) 9:10-22. doi:10.1177/1073858402239587

43. Cannella B, Raine CS. The adhesion molecule and cytokine profile of multiple sclerosis lesions. Ann Neurol (1995) 37:424-35. doi:10.1002/ana. 410370404

44. Bechmann I, Mor G, Nilsen J, Eliza M, Nitsch R, Naftolin F. FasL (CD95L, Apo1L) is expressed in the normal rat and human brain: evidence for the existence of an immunological brain barrier. Glia (1999) 27:62-74. doi:10.1002/ (SICI) 1098-1136(199907)27:1<62::AID-GLIA7>3.0.CO;2-S

45. Choi C, Benveniste EN. Fas ligand/Fas system in the brain: regulator of immune and apoptotic responses. Brain Res Brain Res Rev (2004) 44:65-81. doi:10.1016/j.brainresrev.2003.08.007

46. Gimsa U, ØRen A, Pandiyan P, Teichmann D, Bechmann I, Nitsch R, et al. Astrocytes protect the CNS: antigen-specific $\mathrm{T}$ helper cell responses are inhibited by astrocyte-induced upregulation of CTLA-4 (CD152). J Mol Med (Berl) (2004) 82:364-72. doi:10.1007/s00109-004-0531-6

47. Jensen CJ, Massie A, De Keyser J. Immune players in the CNS: the astrocyte. J Neuroimmune Pharmacol (2013) 8:824-39. doi:10.1007/ s11481-013-9480-6

48. Rothhammer V, Quintana FJ. Control of autoimmune CNS inflammation by astrocytes. Semin Immunopathol (2015) 37:625-38. doi:10.1007/s00281015-0515-3

49. Choi SS, Lee HJ, Lim I, Satoh J, Kim SU. Human astrocytes: secretome profiles of cytokines and chemokines. PLoS One (2014) 9:e92325. doi:10.1371/ journal.pone.0092325

50. Lee SJ, Benveniste EN. Adhesion molecule expression and regulation on cells of the central nervous system. J Neuroimmunol (1999) 98:77-88. doi:10.1016/ S0165-5728(99)00084-3

51. Williams WM, Castellani RJ, Weinberg A, Perry G, Smith MA. Do $\beta$-defensins and other antimicrobial peptides play a role in neuroimmune function and neurodegeneration? Scientific World Journal (2012) 2012:905785. doi:10.1100/2012/905785

52. Mahida YR, Cunliffe RN. Defensins and mucosal protection. Novartis Found Symp (2004) 263:71-7. doi:10.1002/0470090480.ch6 discussion 77-84, 211-8,

53. Chao CC, Lokensgard JR, Sheng WS, Hu S, Peterson PK. IL-1-induced iNOS expression in human astrocytes via NF-kappa B. Neuroreport (1997) 8:3163-6. doi:10.1097/00001756-199709290-00031

54. Sheng WS, Hu S, Feng A, Rock RB. Reactive oxygen species from human astrocytes induced functional impairment and oxidative damage. Neurochem Res (2013) 38:2148-59. doi:10.1007/s11064-013-1123-Z

55. Farina C, Krumbholz M, Giese T, Hartmann G, Aloisi F, Meinl E. Preferential expression and function of toll-like receptor 3 in human astrocytes. J Neuroimmunol (2005) 159:12-9. doi:10.1016/j.jneuroim.2004.09.009

56. Bsibsi M, Ravid R, Gveric D, van Noort JM. Broad expression of toll-like receptors in the human central nervous system. J Neuropathol Exp Neurol (2002) 61:1013-21. doi:10.1093/jnen/61.11.1013

57. Jack CS, Arbour N, Manusow J, Montgrain V, Blain M, McCrea E, et al. TLR signaling tailors innate immune responses in human microglia and astrocytes. J Immunol (2005) 175:4320-30. doi:10.4049/jimmunol.175.7.4320

58. Bsibsi M, Persoon-Deen C, Verwer RW, Meeuwsen S, Ravid R, Van Noort JM. Toll-like receptor 3 on adult human astrocytes triggers production of neuroprotective mediators. Glia (2006) 53:688-95. doi:10.1002/glia.20328
59. Weber F, Meinl E, Aloisi F, Nevinny-Stickel C, Albert E, Wekerle H, et al. Human astrocytes are only partially competent antigen presenting cells. Possible implications for lesion development in multiple sclerosis. Brain (1994) 117:59-69. doi:10.1093/brain/117.1.59

60. Cornet A, Bettelli E, Oukka M, Cambouris C, Avellana-Adalid V, Kosmatopoulos $\mathrm{K}$, et al. Role of astrocytes in antigen presentation and naive T-cell activation. J Neuroimmunol (2000) 106:69-77. doi:10.1016/S01655728(99)00215-5

61. Michel L, Touil H, Pikor NB, Gommerman JL, Prat A, Bar-Or A. B cells in the multiple sclerosis central nervous system: trafficking and contribution to CNS-compartmentalized inflammation. Front Immunol (2015) 6:636. doi:10.3389/fimmu.2015.00636

62. Khan WN. B cell receptor and BAFF receptor signaling regulation of B cell homeostasis. J Immunol (2009) 183:3561-7. doi:10.4049/jimmunol.0800933

63. Krumbholz M, Theil D, Derfuss T, Rosenwald A, Schrader F, Monoranu C-M, et al. BAFF is produced by astrocytes and up-regulated in multiple sclerosis lesions and primary central nervous system lymphoma. J Exp Med (2005) 201:195-200. doi:10.1084/jem.20041674

64. Gavillet M, Allaman I, Magistretti PJ. Modulation of astrocytic metabolic phenotype by proinflammatory cytokines. Glia (2008) 56:975-89. doi:10.1002/glia.20671

65. Fang J, Han D, Hong J, Tan Q, Tian Y. The chemokine, macrophage inflammatory protein- $2 \gamma$, reduces the expression of glutamate transporter- 1 on astrocytes and increases neuronal sensitivity to glutamate excitotoxicity. J Neuroinflammtion (2012) 9:267-267. doi:10.1186/1742-2094-9-267

66. Werner P, Pitt D, Raine CS. Multiple sclerosis: altered glutamate homeostasis in lesions correlates with oligodendrocyte and axonal damage. Ann Neurol (2001) 50:169-80. doi:10.1002/ana.1077

67. Liddelow SA, Barres BA. Reactive astrocytes: production, function, and therapeutic potential. Immunity (2017) 46:957-67. doi:10.1016/j.immuni. 2017.06.006

68. Liddelow SA, Guttenplan KA, Clarke LE, Bennett FC, Bohlen CJ, Schirmer $\mathrm{L}$, et al. Neurotoxic reactive astrocytes are induced by activated microglia. Nature (2017) 541:481-7. doi:10.1038/nature21029

69. Martinez FO, Gordon S. The M1 and M2 paradigm of macrophage activation: time for reassessment. F1000Prime Rep (2014) 6:13. doi:10.12703/P6-13

70. Pekny M, Pekna M, Messing A, Steinhäuser C, Lee J-M, Parpura V, et al. Astrocytes: a central element in neurological diseases. Acta Neuropathol (2016) 131:323-45. doi:10.1007/s00401-015-1513-1

71. Zamanian JL, Xu L, Foo LC, Nouri N, Zhou L, Giffard RG, et al. Genomic analysis of reactive astrogliosis. J Neurosci (2012) 32:6391-410. doi:10.1523/ JNEUROSCI.6221-11.2012

72. Cordiglieri C, Farina C. Astrocytes exert and control immune responses in the brain. Curr Immunol Rev (2010) 6:150. doi:10.2174/157339510791823655

73. Hulshof S, Montagne L, De Groot CJ, Van Der Valk P. Cellular localization and expression patterns of interleukin-10, interleukin-4, and their receptors in multiple sclerosis lesions. Glia (2002) 38:24-35. doi:10.1002/glia.10050

74. Wang D, Ayers MM, Catmull DV, Hazelwood LJ, Bernard CC, Orian JM. Astrocyte-associated axonal damage in pre-onset stages of experimental autoimmune encephalomyelitis. Glia (2005) 51:235-40. doi:10.1002/glia.20199

75. Pham H, Ramp AA, Klonis N, Ng SW, Klopstein A, Ayers MM, et al. The astrocytic response in early experimental autoimmune encephalomyelitis occurs across both the grey and white matter compartments. J Neuroimmunol (2009) 208:30-9. doi:10.1016/j.jneuroim.2008.12.010

76. D'Amelio FE, Smith ME, Eng LF. Sequence of tissue responses in the early stages of experimental allergic encephalomyelitis (EAE): immunohistochemical, light microscopic, and ultrastructural observations in the spinal cord. Glia (1990) 3:229-40. doi:10.1002/glia.440030402

77. Zeinstra E, Wilczak N, De Keyser J. Reactive astrocytes in chronic active lesions of multiple sclerosis express co-stimulatory molecules B7-1 and B7-2. J Neuroimmunol (2003) 135:166-71. doi:10.1016/S0165-5728(02)00462-9

78. Traugott U. Multiple sclerosis: relevance of class I and class II MHCexpressing cells to lesion development. J Neuroimmunol (1987) 16:283-302. doi:10.1016/0165-5728(87)90082-8

79. Meinl E, Aloisi F, Ertl B, Weber F, de Waal Malefyt R, Wekerle H, et al. Multiple sclerosis. Immunomodulatory effects of human astrocytes on T cells. Brain (1994) 117(Pt 6):1323-32. doi:10.1093/brain/117.6.1323 
80. Sørensen TL, Tani M, Jensen J, Pierce V, Lucchinetti C, Folcik VA, et al. Expression of specific chemokines and chemokine receptors in the central nervous system of multiple sclerosis patients. J Clin Invest (1999) 103:807-15. doi:10.1172/JCI5150

81. Ponath G, Lincoln MR, Dahlawi S, Mubarak M, Sumida T, Airas L, et al. Enhanced astrocyte responses are driven by a genetic risk allele associated with multiple sclerosis. bioRxiv (2017). doi:10.1101/206110

82. Love S, Louis D, Ellison DW, Sobel RA, Moore GRW. Chapter 20: Demyelinating diseases. Greenfield's Neuropathology. (Vol. 2) 8th edn. CRC Press (2008). p. 1513-608.

83. Kim RY, Hoffman AS, Itoh N, Ao Y, Spence R, Sofroniew MV, et al. Astrocyte CCL2 sustains immune cell infiltration in chronic experimental autoimmune encephalomyelitis. J Neuroimmunol (2014) 274:53-61. doi:10.1016/ j.jneuroim.2014.06.009

84. Bullard DC, Hu X, Schoeb TR, Collins RG, Beaudet AL, Barnum SR. Intercellular adhesion molecule- 1 expression is required on multiple cell types for the development of experimental autoimmune encephalomyelitis. J Immunol (2007) 178:851-7. doi:10.4049/jimmunol.178.2.851

85. Kipp M, Clarner T, Dang J, Copray S, Beyer C. The cuprizone animal model: new insights into an old story. Acta Neuropathol (2009) 118:723-36. doi:10.1007/s00401-009-0591-3

86. Skripuletz T, Hackstette D, Bauer K, Gudi V, Pul R, Voss E, et al. Astrocytes regulate myelin clearance through recruitment of microglia during cuprizone-induced demyelination. Brain (2013) 136:147-67. doi:10.1093/brain/ aws 262

87. Ragheb S, Li Y, Simon K, VanHaerents S, Galimberti D, De Riz M, et al. Multiple sclerosis: BAFF and CXCL13 in cerebrospinal fluid. Mult Scler (2011) 17:819-29. doi:10.1177/1352458511398887

88. Stern JN, Yaari G, Vander Heiden JA, Church G, Donahue WF, Hintzen RQ, et al. B cells populating the multiple sclerosis brain mature in the draining cervical lymph nodes. Sci Transl Med (2014) 6:248ra107. doi:10.1126/ scitranslmed.3008879

89. Magliozzi R, Howell O, Vora A, Serafini B, Nicholas R, Puopolo M, et al. Meningeal B-cell follicles in secondary progressive multiple sclerosis associate with early onset of disease and severe cortical pathology. Brain (2007) 130:1089-104. doi:10.1093/brain/awm038

90. Srinivasan R, Sailasuta N, Hurd R, Nelson S, Pelletier D. Evidence of elevated glutamate in multiple sclerosis using magnetic resonance spectroscopy at 3 T. Brain (2005) 128:1016-25. doi:10.1093/brain/awh467

91. Baranzini SE, Srinivasan R, Khankhanian P, Okuda DT, Nelson SJ, Matthews PM, et al. Genetic variation influences glutamate concentrations in brains of patients with multiple sclerosis. Brain (2010) 133:2603-11. doi:10.1093/brain/awq192

92. Won JS, Singh AK, Singh I. Lactosylceramide: a lipid second messenger in neuroinflammatory disease. J Neurochem (2007) 1(103 Suppl):180-91. doi:10.1111/j.1471-4159.2007.04822.x

93. Huang EJ, Reichardt LF. Neurotrophins: roles in neuronal development and function. Annu Rev Neurosci (2001) 24:677-736. doi:10.1146/annurev. neuro.24.1.677

94. Lee D-H, Geyer E, Flach A-C, Jung K, Gold R, Flügel A, et al. Central nervous system rather than immune cell-derived BDNF mediates axonal protective effects early in autoimmune demyelination. Acta Neuropathol (2012) 123:247-58. doi:10.1007/s00401-011-0890-3

95. Linker RA, Lee DH, Demir S, Wiese S, Kruse N, Siglienti I, et al. Functional role of brain-derived neurotrophic factor in neuroprotective autoimmunity: therapeutic implications in a model of multiple sclerosis. Brain (2010) 133:2248-63. doi:10.1093/brain/awq179

96. Fulmer CG, VonDran MW, Stillman AA, Huang Y, Hempstead BL, Dreyfus CF. Astrocyte-derived BDNF supports myelin protein synthesis after cuprizone-induced demyelination. J Neurosci (2014) 34:8186-96. doi:10.1523/JNEUROSCI.4267-13.2014

97. Colombo E, Cordiglieri C, Melli G, Newcombe J, Krumbholz M, Parada LF, et al. Stimulation of the neurotrophin receptor TrkB on astrocytes drives nitric oxide production and neurodegeneration. J Exp Med (2012) 209:521. doi:10.1084/jem.20110698

98. Stadelmann C, Kerschensteiner M, Misgeld T, Brück W, Hohlfeld R, Lassmann H. BDNF and gp145trkB in multiple sclerosis brain lesions: neuroprotective interactions between immune and neuronal cells? Brain (2002) 125:75-85. doi:10.1093/brain/awf015
99. Dodel RC, Du Y, Bales KR, Gao F, Paul SM. Sodium salicylate and 17beta-estradiol attenuate nuclear transcription factor NF-kappaB translocation in cultured rat astroglial cultures following exposure to amyloid A beta(1-40) and lipopolysaccharides. J Neurochem (1999) 73:1453-60. doi:10.1046/j.1471-4159.1999.0731453.x

100. Tenenbaum M, Azab AN, Kaplanski J. Effects of estrogen against LPSinduced inflammation and toxicity in primary rat glial and neuronal cultures. J Endotoxin Res (2007) 13:158-66. doi:10.1177/0968051907080428

101. Cerciat M, Unkila M, Garcia-Segura LM, Arevalo MA. Selective estrogen receptor modulators decrease the production of interleukin- 6 and interferon-gamma-inducible protein-10 by astrocytes exposed to inflammatory challenge in vitro. Glia (2010) 58:93-102. doi:10.1002/glia.20904

102. Spence RD, Hamby ME, Umeda E, Itoh $\mathrm{N}$, Du S, Wisdom AJ, et al. Neuroprotection mediated through estrogen receptor- $\alpha$ in astrocytes. Proc Natl Acad Sci U S A (2011) 108:8867-72. doi:10.1073/pnas.1103833108

103. Spence RD, Wisdom AJ, Cao Y, Hill HM, Mongerson CRL, Stapornkul B, et al. estrogen mediates neuroprotection and anti-inflammatory effects during EAE through ER $\alpha$ signaling on astrocytes but not through ER $\beta$ signaling on astrocytes or neurons. J Neurosci (2013) 33:10924-33. doi:10.1523/ JNEUROSCI.0886-13.2013

104. Luchetti S, van Eden CG, Schuurman K, van Strien ME, Swaab DF, Huitinga I. Gender differences in multiple sclerosis: induction of estrogen signaling in male and progesterone signaling in female lesions. J Neuropathol Exp Neurol (2014) 73:123-35. doi:10.1097/NEN.0000000000000037

105. Noorbakhsh F, Ellestad KK, Maingat F, Warren KG, Han MH, Steinman L, et al. Impaired neurosteroid synthesis in multiple sclerosis. Brain (2011) 134:2703-21. doi:10.1093/brain/awr200

106. Touil T, Fitzgerald D, Zhang GX, Rostami A, Gran B. Cutting edge: TLR3 stimulation suppresses experimental autoimmune encephalomyelitis by inducing endogenous IFN-beta. J Immunol (2006) 177:7505-9. doi:10.4049/ jimmunol.177.11.7505

107. Marta M, Andersson A, Isaksson M, Kampe O, Lobell A. Unexpected regulatory roles of TLR4 and TLR9 in experimental autoimmune encephalomyelitis. Eur J Immunol (2008) 38:565-75. doi:10.1002/eji.200737187

108. Berer K, Mues M, Koutrolos M, Rasbi ZA, Boziki M, Johner C, et al. Commensal microbiota and myelin autoantigen cooperate to trigger autoimmune demyelination. Nature (2011) 479:538-41. doi:10.1038/nature10554

109. Jangi S, Gandhi R, Cox LM, Li N, von Glehn F, Yan R, et al. Alterations of the human gut microbiome in multiple sclerosis. Nat Commun (2016) 7:12015. doi:10.1038/ncomms 12015

110. Braniste V, Al-Asmakh M, Kowal C, Anuar F, Abbaspour A, Toth M, et al. The gut microbiota influences blood-brain barrier permeability in mice. $\mathrm{Sci}$ Transl Med (2014) 6:263ra158. doi:10.1126/scitranslmed.3009759

111. Fessler EB, Chibane FL, Wang Z, Chuang DM. Potential roles of HDAC inhibitors in mitigating ischemia-induced brain damage and facilitating endogenous regeneration and recovery. Curr Pharm Des (2013) 19:5105-20. doi:10.2174/1381612811319280009

112. Michel L, Prat A. One more role for the gut: microbiota and blood brain barrier. Ann Transl Med (2016) 4:15. doi:10.3978/j.issn.2305-5839.2015.10.16

113. Shih R-H, Wang C-Y, Yang C-M. NF-kappaB signaling pathways in neurological inflammation: a mini review. Front Mol Neurosci (2015) 8:77. doi: $10.3389 /$ fnmol.2015.00077

114. Hayden MS, Ghosh S. NF-kappaB, the first quarter-century: remarkable progress and outstanding questions. Genes Dev (2012) 26:203-34. doi:10.1101/gad.183434.111

115. Mc Guire C, Prinz M, Beyaert R, van Loo G. Nuclear factor kappa B (NF-кB) in multiple sclerosis pathology. Trends Mol Med (2013) 19:604-13. doi:10.1016/j.molmed.2013.08.001

116. Kawai T, Akira S. Signaling to NF-kB by Toll-like receptors. Trends Mol Med (2007) 13:460-9. doi:10.1016/j.molmed.2007.09.002

117. Brambilla R, Persaud T, Hu X, Karmally S, Shestopalov VI, Dvoriantchikova G, et al. Transgenic inhibition of astroglial NF- $\mathrm{kB}$ improves functional outcome in experimental autoimmune encephalomyelitis by suppressing chronic central nervous system inflammation. JImmunol (2009) 182:2628-40. doi:10.4049/ jimmunol.0802954

118. Brambilla R, Bracchi-Ricard V, Hu WH, Frydel B, Bramwell A, Karmally S, et al. Inhibition of astroglial nuclear factor kappaB reduces inflammation and improves functional recovery after spinal cord injury. J Exp Med (2005) 202:145-56. doi:10.1084/jem.20041918 
119. Dvoriantchikova G, Barakat D, Brambilla R, Agudelo C, Hernandez E, Bethea JR, et al. Inactivation of astroglial NF-kappa B promotes survival of retinal neurons following ischemic injury. Eur J Neurosci (2009) 30:175-85. doi:10.1111/j.1460-9568.2009.06814.x

120. Kang Z, Wang C, Zepp J, Wu L, Sun K, Zhao J, et al. Actl mediates IL-17induced EAE pathogenesis selectively in NG2(+) glial cells. Nat Neurosci (2013) 16:1401-8. doi:10.1038/nn.3505

121. Rothhammer V, Mascanfroni ID, Bunse L, Takenaka MC, Kenison JE, Mayo L, et al. Type I interferons and microbial metabolites of tryptophan modulate astrocyte activity and central nervous system inflammation via the aryl hydrocarbon receptor. Nat Med (2016) 22:586-97. doi:10.1038/ nm.4106

122. Vogel CF, Matsumura F. A new cross-talk between the aryl hydrocarbon receptor and RelB, a member of the NF-kappaB family. Biochem Pharmacol (2009) 77:734-45. doi:10.1016/j.bcp.2008.09.036

123. Housley WJ, Fernandez SD, Vera K, Murikinati SR, Grutzendler J, Cuerdon N, et al. Genetic variants associated with autoimmunity drive NFKB signaling and responses to inflammatory stimuli. Sci Transl Med (2015) 7:ra93-291. doi:10.1126/scitranslmed.aaa9223

124. Nicolas CS, Amici M, Bortolotto ZA, Doherty A, Csaba Z, Fafouri A, et al. The role of JAK-STAT signaling within the CNS. JAKSTAT (2013) 2:e22925. doi:10.4161/jkst.22925

125. Ernst M, Jenkins BJ. Acquiring signalling specificity from the cytokine receptor gp130. Trends Genet (2004) 20:23-32. doi:10.1016/j.tig.2003.11.003

126. Park EJ, Ji KA, Jeon SB, Choi WH, Han IO, You HJ, et al. Racl contributes to maximal activation of STAT1 and STAT3 in IFN-gamma-stimulated rat astrocytes. J Immunol (2004) 173:5697-703. doi:10.4049/jimmunol.173.9.5697

127. Choi WH, Ji KA, Jeon SB, Yang MS, Kim H, Min KJ, et al. Anti-inflammatory roles of retinoic acid in rat brain astrocytes: suppression of interferon-gamma-induced JAK/STAT phosphorylation. Biochem Biophys Res Commun (2005) 329:125-31. doi:10.1016/j.bbrc.2005.01.110

128. Herrmann JE, Imura T, Song B, Qi J, Ao Y, Nguyen TK, et al. STAT3 is a critical regulator of astrogliosis and scar formation after spinal cord injury. J Neurosci (2008) 28:7231-43. doi:10.1523/JNEUROSCI.1709-08.2008

129. Okada S, Nakamura M, Katoh H, Miyao T, Shimazaki T, Ishii K, et al. Conditional ablation of Stat 3 or Socs 3 discloses a dual role for reactive astrocytes after spinal cord injury. Nat Med (2006) 12:829-34. doi:10.1038/ nm 1425

130. Haroon F, Drogemuller K, Handel U, Brunn A, Reinhold D, Nishanth G, et al. Gp130-dependent astrocytic survival is critical for the control of autoimmune central nervous system inflammation. J Immunol (2011) 186:6521-31. doi:10.4049/jimmunol.1001135

131. Sticozzi C, Belmonte G, Meini A, Carbotti P, Grasso G, Palmi M. IL-1beta induces GFAP expression in vitro and in vivo and protects neurons from traumatic injury-associated apoptosis in rat brain striatum via NFkappaB/Ca(2)(+)-calmodulin/ERK mitogen-activated protein kinase signaling pathway. Neuroscience (2013) 252:367-83. doi:10.1016/j. neuroscience.2013.07.061

132. Kim JA, Yun H-M, Jin P, Lee HP, Han JY, Udumula V, et al. Inhibitory effect of a 2,4-bis(4-hydroxyphenyl)-2-butenal diacetate on neuro-inflammatory reactions via inhibition of STAT1 and STAT3 activation in cultured astrocytes and microglial BV-2 cells. Neuropharmacology (2014) 79:476-87. doi:10.1016/j.neuropharm.2013.06.032

133. Sun L, Li Y, Jia X, Wang Q, Li Y, Hu M, et al. Neuroprotection by IFN- $\gamma$ via astrocyte-secreted IL-6 in acute neuroinflammation. Oncotarget (2017) 8:40065-78. doi:10.18632/oncotarget.16990

134. Kimura A, Kishimoto T. IL-6: regulator of TREG/Th17 balance. Eur J Immunol (2010) 40:1830-5. doi:10.1002/eji.201040391

135. Erta M, Quintana A, Hidalgo J. Interleukin-6, a major cytokine in the central nervous system. Int J Biol Sci (2012) 8:1254-66. doi:10.7150/ijbs.4679

136. Comi G, Jeffery D, Kappos L, Montalban X, Boyko A, Rocca MA, et al. Placebo-controlled trial of oral laquinimod for multiple sclerosis. $N$ Engl J Med (2012) 366:1000-9. doi:10.1056/NEJMoa1104318

137. Barkhof F, Giovannoni G, Hartung H-P, Cree B, Uccelli A, Sormani MP, et al. ARPEGGIO: a randomized, placebo-controlled study to evaluate oral laquinimod in patients with primary progressive multiple sclerosis (PPMS) (P7.210). Neurology (2015) 84:P7.210.

138. Kaye J, Piryatinsky V, Birnberg T, Hingaly T, Raymond E, Kashi R, et al. Laquinimod arrests experimental autoimmune encephalomyelitis by activating the aryl hydrocarbon receptor. Proc Natl Acad Sci U S A (2016) 113:E6145-52. doi:10.1073/pnas.1607843113

139. Abel J, Haarmann-Stemmann T. An introduction to the molecular basics of aryl hydrocarbon receptor biology. Biol Chem (2010) 391:1235-48. doi:10.1515/BC.2010.128

140. Denison MS, Nagy SR. Activation of the aryl hydrocarbon receptor by structurally diverse exogenous and endogenous chemicals. Annu Rev Pharmacol Toxicol (2003) 43:309-34. doi:10.1146/annurev.pharmtox.43. 100901.135828

141. Fritsche E, Schafer C, Calles C, Bernsmann T, Bernshausen T, Wurm M, et al. Lightening up the UV response by identification of the arylhydrocarbon receptor as a cytoplasmatic target for ultraviolet B radiation. Proc Natl Acad Sci U S A (2007) 104:8851-6. doi:10.1073/pnas.0701764104

142. Madhukar BV, Brewster DW, Matsumura F. Effects of in vivo-administered 2,3,7,8-tetrachlorodibenzo-p-dioxin on receptor binding of epidermal growth factor in the hepatic plasma membrane of rat, guinea pig, mouse, and hamster. Proc Natl Acad Sci U S A (1984) 81:7407-11. doi:10.1073/ pnas.81.23.7407

143. Oesch-Bartlomowicz B, Huelster A, Wiss O, Antoniou-Lipfert P, Dietrich C, Arand $\mathrm{M}$, et al. Aryl hydrocarbon receptor activation by cAMP vs. dioxin: divergent signaling pathways. Proc Natl Acad Sci U S A (2005) 102:9218-23. doi:10.1073/pnas.0503488102

144. Vogel CF, Sciullo E, Li W, Wong P, Lazennec G, Matsumura F. RelB, a new partner of aryl hydrocarbon receptor-mediated transcription. Mol Endocrinol (2007) 21:2941-55. doi:10.1210/me.2007-0211

145. Tian Y, Rabson AB, Gallo MA. Ah receptor and NF-kappaB interactions: mechanisms and physiological implications. Chem Biol Interact (2002) 141:97-115. doi:10.1016/S0009-2797(02)00068-6

146. Vogel CFA, Haarmann-Stemmann T. The aryl hydrocarbon receptor repressor - More than a simple feedback inhibitor of AhR signaling: clues for its role in inflammation and cancer. Curr Opin Toxicol (2017) 2:109-19. doi:10.1016/j.cotox.2017.02.004

147. Wegner C, Stadelmann C, Pfortner R, Raymond E, Feigelson S, Alon R, et al. Laquinimod interferes with migratory capacity of $\mathrm{T}$ cells and reduces IL-17 levels, inflammatory demyelination and acute axonal damage in mice with experimental autoimmune encephalomyelitis. J Neuroimmunol (2010) 227:133-43. doi:10.1016/j.jneuroim.2010.07.009

148. Yang JS, Xu LY, Xiao BG, Hedlund G, Link H. Laquinimod (ABR-215062) suppresses the development of experimental autoimmune encephalomyelitis, modulates the Th1/Th2 balance and induces the Th3 cytokine TGF-beta in Lewis rats. J Neuroimmunol (2004) 156:3-9. doi:10.1016/j. jneuroim.2004.02.016

149. Bruck W, Pfortner R, Pham T, Zhang J, Hayardeny L, Piryatinsky V, et al. Reduced astrocytic NF-kappaB activation by laquinimod protects from cuprizone-induced demyelination. Acta Neuropathol (2012) 124:411-24. doi:10.1007/s00401-012-1009-1

150. Thone J, Ellrichmann G, Seubert S, Peruga I, Lee DH, Conrad R, et al. Modulation of autoimmune demyelination by laquinimod via induction of brain-derived neurotrophic factor. Am JPathol (2012) 180:267-74 doi:10.1016/j.ajpath.2011.09.037

151. Fox RJ, Miller DH, Phillips JT, Hutchinson M, Havrdova E, Kita M, et al. Placebo-controlled phase 3 study of oral BG-12 or glatiramer in multiple sclerosis. N Engl J Med (2012) 367:1087-97. doi:10.1056/NEJMoa 1206328

152. Gold R, Kappos L, Arnold DL, Bar-Or A, Giovannoni G, Selmaj K, et al. Placebo-controlled phase 3 study of oral BG-12 for relapsing multiple sclerosis. N Engl J Med (2012) 367:1098-107. doi:10.1056/NEJMoa1114287

153. Biogen axes $11 \%$ of Workforce in Restructuring. New Rochelle, NY: Genetic Engineering \& Biotechnology News (2015). Available from: http://www. genengnews.com/gen-news-highlights/biogen-axes-11-of-workforcein-restructuring/81251879

154. Scannevin RH, Chollate S, Jung MY, Shackett M, Patel H, Bista P, et al. Fumarates promote cytoprotection of central nervous system cells against oxidative stress via the nuclear factor (Erythroid-Derived 2)-like 2 pathway. J Pharmacol Exp Ther (2012) 341:274. doi:10.1124/jpet.111.190132

155. Lehmann JCU, Listopad JJ, Rentzsch CU, Igney FH, von Bonin A, Hennekes $\mathrm{HH}$, et al. Dimethylfumarate induces immunosuppression via glutathione depletion and subsequent induction of heme oxygenase 1 . J Invest Dermatol (2007) 127:835-45. doi:10.1038/sj.jid.5700686 
156. Gold R, Linker RA, Stangel M. Fumaric acid and its esters: an emerging treatment for multiple sclerosis with antioxidative mechanism of action. Clin Immunol (2012) 142:44-8. doi:10.1016/j.clim.2011.02.017

157. Brennan MS, Matos MF, Li B, Hronowski X, Gao B, Juhasz P, et al. Dimethyl fumarate and monoethyl fumarate exhibit differential effects on KEAP1, NRF2 activation, and glutathione depletion in vitro. PLoS One (2015) 10:e0120254. doi:10.1371/journal.pone.0120254

158. Itoh K, Wakabayashi N, Katoh Y, Ishii T, Igarashi K, Engel JD, et al. Keap1 represses nuclear activation of antioxidant responsive elements by $\mathrm{Nrf2}$ through binding to the amino-terminal Neh2 domain. Genes Dev (1999) 13:76-86. doi:10.1101/gad.13.1.76

159. Gillard GO, Collette B, Anderson J, Chao J, Scannevin RH, Huss DJ, et al. DMF, but not other fumarates, inhibits NF- $\kappa \mathrm{B}$ activity in vitro in an Nrf2independent manner. JNeuroimmunol (2015) 283:74-85. doi:10.1016/j. jneuroim.2015.04.006

160. Blewett MM, Xie J, Zaro BW, Backus KM, Altman A, Teijaro JR, et al. Chemical proteomic map of dimethyl fumarate-sensitive cysteines in primary human T cells. Sci Signal (2016) 9:rs10-10. doi:10.1126/scisignal.aaf7694

161. Diebold M, Sievers C, Bantug G, Sanderson N, Kappos L, Kuhle J, et al. Dimethyl fumarate influences innate and adaptive immunity in multiple sclerosis. J Autoimmun (2017) 86:39-50. doi:10.1016/j.jaut.2017.09.009

162. Brennan MS, Matos MF, Richter KE, Li B, Scannevin RH. The NRF2 transcriptional target, OSGIN1, contributes to monomethyl fumarate-mediated cytoprotection in human astrocytes. Sci Rep (2017) 7:42054. doi:10.1038/ srep42054

163. Magliozzi R, Howell OW, Reeves C, Roncaroli F, Nicholas R, Serafini B, et al. of neuronal loss and meningeal inflammation in multiple sclerosis. Ann Neurol (2010) 68:477-93. doi:10.1002/ana.22230

164. Galloway DA, Williams JB, Moore CS. Effects of fumarates on inflammatory human astrocyte responses and oligodendrocyte differentiation. Ann Clin Transl Neurol (2017) 4:381-91. doi:10.1002/acn3.414

165. Kappos L, Radue EW, O’Connor P, Polman C, Hohlfeld R, Calabresi P, et al. A placebo-controlled trial of oral fingolimod in relapsing multiple sclerosis. N Engl J Med (2010) 362:387-401. doi:10.1056/NEJMoa0909494

166. Calabresi PA, Radue EW, Goodin D, Jeffery D, Rammohan KW, Reder AT, et al. Safety and efficacy of fingolimod in patients with relapsing-remitting multiple sclerosis (FREEDOMS II): a double-blind, randomised, placebo-controlled, phase 3 trial. Lancet Neurol (2014) 13:545-56. doi:10.1016/ S1474-4422(14)70049-3

167. Smith AL, Cohen JA. Multiple sclerosis: fingolimod failure in progressive MS INFORMS future trials. Nat Rev Neurol (2016) 12:253-4. doi:10.1038/ nrneurol.2016.37

168. Fox RJ. Effects of siponimod on MRI outcomes in patients with secondary progressive multiple sclerosis: results of the phase 3 EXPAND study. ECTRIMS Online Libr (2017) 26:202482.

169. Matloubian M, Lo CG, Cinamon G, Lesneski MJ, Xu Y, Brinkmann V, et al. Lymphocyte egress from thymus and peripheral lymphoid organs is dependent on S1P receptor 1. Nature (2004) 427:355-60. doi:10.1038/ nature 02284

170. Pham TH, Okada T, Matloubian M, Lo CG, Cyster JG. S1P1 receptor signaling overrides retention mediated by $\mathrm{G}$ alpha i-coupled receptors to promote T cell egress. Immunity (2008) 28:122-33. doi:10.1016/j.immuni.2007.11.017

171. Pebay A, Toutant M, Premont J, Calvo CF, Venance L, Cordier J, et al. Sphingosine-1-phosphate induces proliferation of astrocytes: regulation by intracellular signalling cascades. Eur J Neurosci (2001) 13:2067-76. doi:10.1046/j.0953-816x.2001.01585.x

172. Mullershausen F, Craveiro LM, Shin Y, Cortes-Cros M, Bassilana F, Osinde M, et al. Phosphorylated FTY720 promotes astrocyte migration through sphingosine-1-phosphate receptors. J Neurochem (2007) 102:1151-61. doi:10.1111/j.1471-4159.2007.04629.x

173. Jaillard C, Harrison S, Stankoff B, Aigrot MS, Calver AR, Duddy G, et al. Edg8/S1P5: an oligodendroglial receptor with dual function on process retraction and cell survival. J Neurosci (2005) 25:1459-69. doi:10.1523/ JNEUROSCI.4645-04.2005

174. Saini HS, Coelho RP, Goparaju SK, Jolly PS, Maceyka M, Spiegel S, et al. Novel role of sphingosine kinase 1 as a mediator of neurotrophin-3 action in oligodendrocyte progenitors. J Neurochem (2005) 95:1298-310. doi:10.1111/j.1471-4159.2005.03451.x

175. MacLennan AJ, Devlin BK, Marks L, Gaskin AA, Neitzel KL, Lee N. Antisense studies in PC12 cells suggest a role for H218, a sphingosine 1-phosphate receptor, in growth-factor-induced cell-cell interaction and neurite outgrowth. Dev Neurosci (2000) 22:283-95. doi:10.1159/000017452

176. Harada J, Foley M, Moskowitz MA, Waeber C. Sphingosine-1-phosphate induces proliferation and morphological changes of neural progenitor cells. J Neurochem (2004) 88:1026-39. doi:10.1046/j.1471-4159.2003.02219.x

177. Sato K, Tomura H, Igarashi Y, Ui M, Okajima F. Exogenous sphingosine 1-phosphate induces neurite retraction possibly through a cell surface receptor in PC12 cells. Biochem Biophys Res Commun (1997) 240:329-34. doi:10.1006/bbrc.1997.7666

178. Choi JW, Gardell SE, Herr DR, Rivera R, Lee C-W, Noguchi K, et al. FTY720 (fingolimod) efficacy in an animal model of multiple sclerosis requires astrocyte sphingosine 1-phosphate receptor 1 (S1P1) modulation. Proc Natl Acad Sci U S A (2011) 108:751-6. doi:10.1073/pnas.1014154108

179. Malchinkhuu E, Sato K, Muraki T, Ishikawa K, Kuwabara A, Okajima F. Assessment of the role of sphingosine 1-phosphate and its receptors in high-density lipoprotein-induced stimulation of astroglial cell function. Biochem J (2003) 370:817-27. doi:10.1042/bj20020867

180. Van Doorn R, Van Horssen J, Verzijl D, Witte M, Ronken E, Van Het Hof B, et al. Sphingosine 1-phosphate receptor 1 and 3 are upregulated in multiple sclerosis lesions. Glia (2010) 58:1465-76. doi:10.1002/glia.21021

181. Colombo E, Di Dario M, Capitolo E, Chaabane L, Newcombe J, Martino $\mathrm{G}$, et al. Fingolimod may support neuroprotection via blockade of astrocyte nitric oxide. Ann Neurol (2014) 76:325-37. doi:10.1002/ana.24217

182. Hoffmann FS, Hofereiter J, Rubsamen H, Melms J, Schwarz S, Faber H, et al. Fingolimod induces neuroprotective factors in human astrocytes. J Neuroinflammation (2015) 12:184. doi:10.1186/s12974-015-0393-6

183. Wu C, Leong SY, Moore CS, Cui QL, Gris P, Bernier L-P, et al. Dual effects of daily FTY720 on human astrocytes in vitro: relevance for neuroinflammation. J Neuroinflammation (2013) 10:41-41. doi:10.1186/1742-2094-10-41

184. Cohen JA, Chun J. Mechanisms of fingolimod's efficacy and adverse effects in multiple sclerosis. Ann Neurol (2011) 69:759-77. doi:10.1002/ana.22426

185. Edling A, Woodworth L, Agrawal R, Mahan A, Garron T, Hagan N, et al. Teriflunomide impacts primary microglia and astrocyte functions in vitro (P2.348). Neurology (2017) 88:P2.348.

186. Miljkovic D, Samardzic T, Mostarica Stojkovic M, Stosic-Grujicic S, Popadic D, Trajkovic V. Leflunomide inhibits activation of inducible nitric oxide synthase in rat astrocytes. Brain Res (2001) 889:331-8. doi:10.1016/ S0006-8993(00)03181-4

187. Limsakun T, Menguy-Vacheron F. Pharmacokinetics of oral teriflunomide, a novel oral disease-modifying agent under investigation for the treatment of multiple sclerosis. Neurology (2010) 74:A415.

188. Tallantyre E, Evangelou N, Constantinescu CS. Spotlight on teriflunomide. Int MS J (2008) 15:62-8.

Conflict of Interest Statement: The authors declare that the research was conducted in the absence of any commercial or financial relationships that could be construed as a potential conflict of interest.

Copyright (C) 2018 Ponath, Park and Pitt. This is an open-access article distributed under the terms of the Creative Commons Attribution License (CC BY). The use, distribution or reproduction in other forums is permitted, provided the original author(s) and the copyright owner are credited and that the original publication in this journal is cited, in accordance with accepted academic practice. No use, distribution or reproduction is permitted which does not comply with these terms. 